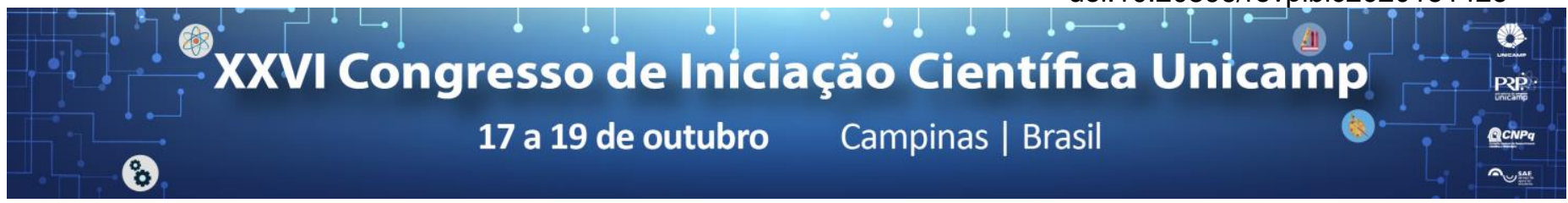

\title{
Avaliação do Consumo de Energia Elétrica em um Refrigerador Doméstico
}

\section{Leonardo Grisi, Laura Luise Zonta, Mayara G. S. Amorim, Professor Flavio Vasconcelos da Silva (FEQ/Unicamp)}

\section{Resumo}

Os sistemas de refrigeração são grandes consumidores de energia e estão presentes nos setores industrial, comercial e residencial, com importantes aplicações na vida cotidiana. Neste contexto, medidas de melhoria da eficiência energética em aplicações de refrigeração recebem especial atenção. Segundo dados oficias, os motores elétricos de indução (de uso extensivo em sistema de refrigeração) detêm $49 \%$ do consumo de energia elétrica numa instalação. Considerando-se o setor doméstico, os equipamentos de refrigeração são responsáveis por aproximadamente $65 \%$ do consumo total de uma residência. Assim, neste estudo foi realizada uma avaliação e uma quantificação do consumo de energia de um refrigerador doméstico submetido a diferentes condições de operação. Também foram analisados os efeitos da abertura de porta e efeito de maus hábitos cotidianos no consumo global do refrigerador. Foi observado um considerável aumento do consumo de energia elétrica mensal $(51,35 \mathrm{kWh})$ relacionado à abertura de portas a um aumento do custo de $\mathrm{R} \$ 21,21$ por mês na pior condição estudada.

\section{Palavras-chave:}

Refrigeração, Energia, Instrumentação.

\section{Introdução}

*Geladeira - Alto Consumo de Energia Elétrica

*Hipótese adotada:

"É possível quantificar o impacto do Tempo de abertura da porta e da obstrução do condensador no consumo de energia elétrica de um refrigerador doméstico"

\section{Resultados e Discussão}

\section{- Sistema de Supervisão e Aquisição de Dados}

Inicialmente foi desenvolvido um sistema para a aquisição dos valores das temperaturas internas do refrigerador durantes os ensaios.

Figura 1 - Tela de Supervisão das Temperaturas Internas do Refrigerador Doméstico.

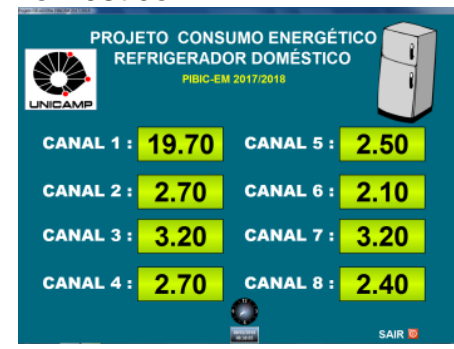

\section{- Efeito da Abertura de Portas}

Figura 2 - Consumo Mensal (a) e Custo adicional na conta (b) para diferentes graus de abertura de porta.

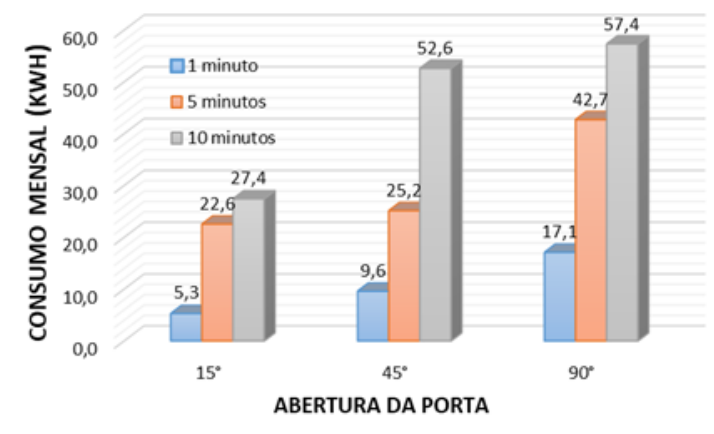

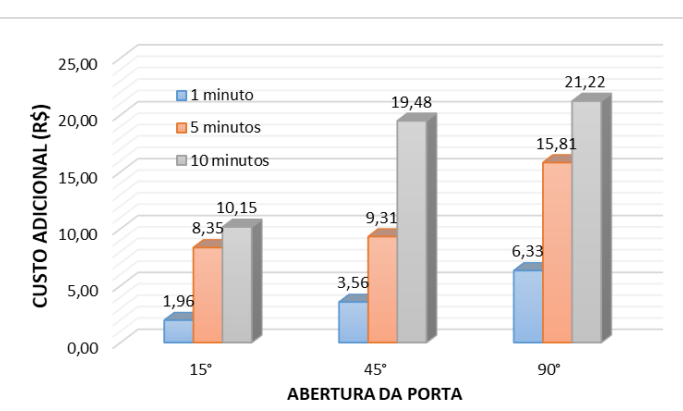

(b)

Observou-se claramente $\mathrm{o}^{(\mathrm{b})}$ efeito danoso da abertura da porta no aumento do consumo de energia, principalmente, como esperado como maior tempo e maior abertura.

\section{- Efeito da Obstrução do Condensador}

Figura 3 - Consumo Mensal (a) e Custo adicional na conta (b) para diferentes graus de abertura de porta.

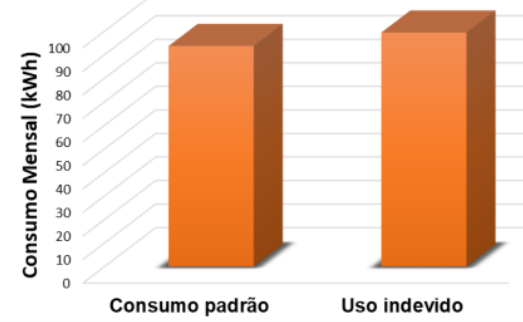

A obstrução do condensador (para secagem de roupas, toalhas, etc) causou um aumento de aproximadamente 6 $\mathrm{kWh}$ mensal. Aparentemente um valor pequeno, porém causa outros impactos no funcionamento do refrigerador.

\section{Conclusões e Agradecimentos}

*O refrigerador doméstico parcela significativa no consumo de energia. A abertura da porta tem um grande impacto no aumento deste consumo. A obstrução do condensador traz um aumento no consumo de energia.

*Agradecemos à UNICAMP e à FAPESP pelo apoio à realização deste trabalho.

${ }_{1}$ Azevedo, A. C. Desempenho de Refrigeradores Domésticos no Contexto da Qualidade da Energia Elétrica, Dissertação de Mestrado, Universidade Federal de Uberlândia. 2003. 